\title{
Mechanical properties of prestressing steel in and after fire
}

\section{Li Zhang}

PhD Student, Department of Civil Engineering, The University of Hong Kong, Hong Kong, China

Ya Wei

Former PhD Student, Department of Civil Engineering, The University of Hong Kong, Hong Kong, China

\author{
Francis T. K. Au \\ Professor, Department of Civil Engineering, The University of Hong Kong, \\ Hong Kong, China \\ Jing Li \\ Associate Professor, Department of Civil Engineering, South China \\ University of Technology, Guangzhou, China
}

Knowledge of the mechanical properties of prestressing steel at elevated temperatures and after cooling is essential to the fire resistance design and post-fire evaluation of the residual load-carrying capacity of prestressed concrete structures. Experiments were carried out using an accurate testing system for the development of empirical formulae to predict the deterioration of prestressing steel at elevated temperatures and after cooling. The helical structure of commonly used seven-wire strands allowed estimation of the mechanical properties of the strand based on those of the central wire. Only the central wire of the strand was thus tested, which enabled better clamping and control and hence more accurate measurements. Grade 1860 strands conforming to GB/T 5224, mostly used in Mainland China, and grade 1860 strands conforming to BS 5896, used in Europe and other countries, were tested. Consistent models for the reduction factors of various properties were developed. Some strands extracted from prestressed concrete specimens after fire testing were also tested for verification.

\section{Notation}

E Young's modulus of prestressing wire at ambient temperature

$E(T) \quad$ Young's modulus of prestressing wire at temperature $T$

$E_{\text {ac }}(T)$ Young's modulus of prestressing wire after cooling from temperature $T$

$f(T) \quad$ reduction factor at temperature $T$

$f_{\mathrm{u}} \quad$ ultimate strength at ambient temperature

$f_{\mathrm{u}}(T) \quad$ ultimate strength at temperature $T$

$f_{\text {uac }}(T)$ ultimate strength after cooling from temperature $T$

$f_{\text {yac }}(T)$ yield strength of prestressing wire after cooling from temperature $T$

$f_{0 \cdot 2 \%} \quad 0 \cdot 2 \%$ proof stress at ambient temperature

$f_{0 \cdot 2}(T) \quad 0 \cdot 2 \%$ proof stress at temperature $T$

\section{Introduction}

Prestressed concrete is often used to achieve large span to depth ratios, cost-effectiveness and enhanced load-carrying capacity, but it is prone to fire damage, particularly in thin slabs. Bailey and Ellobody (2009) conducted fire tests on unbonded one-way post-tensioned concrete slabs and investigated their overall structural behaviour in fire. Zhang et al. (2014) studied the behaviour of two-way reinforced concrete slabs in fire. A structural fire engineering assessment of the response in and after fire requires consideration of the thermal load, the thermal and mechanical properties of materials and their interaction. When prestressing steel is heated above $300^{\circ} \mathrm{C}$, the structure is affected, possibly resulting in collapse. Although the Young's modulus of steel is not much affected after cooling, the 'yield' strength, ultimate strength and ductility will degrade depending on the peak temperature reached, and they thus need to be properly assessed.

Empirical equations for the Young's modulus and yield strength of grade 1670 prestressing wires used in China at temperatures up to $600^{\circ} \mathrm{C}$ were proposed by Fan and $\mathrm{Lv}$ (2001). Fan (2004) further tested grade 1860 prestressing strands under different cooling processes, and proposed cubic polynomials for Young's modulus, yield strength and ultimate strength after cooling. Hertz $(2004,2006)$ proposed an equation for the deterioration of quenched and tempered prestressing steel and of quenched and self-tempered reinforcement. Neves et al. (1996) conducted tests and found the residual strength of reinforcing and prestressing steel wires to depend on the cooling process. Atienza and Elices (2009) investigated the tensile strength of prestressing wires in and after fire up to $600^{\circ} \mathrm{C}$. Gálvez et al. (2011) studied the strain rate effect on the tensile strength of prestressing wires at elevated temperatures. The ultimate strength and thermal creep effect of the central wires of prestressing strands conforming to BS 5896 (BSI, 2012) at elevated temperature were investigated by optical strain measurement (Gales et al., 2012). 
Performance-based design, instead of the simpler prescriptivebased design, is often adopted as it can achieve safety, economy and stability (Pang, 2006). BS EN 1992-1-2 (Eurocode 2) provides reduction factors for prestressing steel at elevated temperatures but not those for residual properties after cooling (BSI, 2004). The work described in this paper attempted to develop consistent models for predicting the mechanical properties of prestressing steel conforming to GB/T 5224 (SAC, 2003) and BS 5896 (BSI, 2012), used extensively in Mainland China and Europe respectively, at elevated temperatures and after cooling.

\section{Axial response of straight seven-wire prestressing strands}

Strands and wires are usually tested as straight specimens in regular testing. In applications of prestressed concrete structures, the cable curvature is normally small compared with the cable size and hence the test results will be applicable in this case. By studying the axial response of a straight seven-wire prestressing strand, it is possible to relate the response of the strand to that of the central wire.

Costello (1997) presented an analytical model to determine the axial static response of a simple straight strand by considering the respective contributions from the straight central wire and the outer helical wires. That analysis assumed an elastic response, frictionless contact between the wires and that the central wire was of sufficient size to prevent the outer wires touching each other. In the tested prestressing steel strand of nominal diameter $12.7 \mathrm{~mm}$ conforming to $\mathrm{GB} / \mathrm{T} 5224$, the diameter of the central wire was determined to be $4.35 \mathrm{~mm}$. The diameter of the helical wire was measured and taken as the same although, strictly speaking, it should be slightly smaller in order to avoid the helical wires contacting each other. The pitch of the helical wires is defined as the axial distance along the length of strand that a helical wire twists around the central wire by one revolution. In this case, the pitch was taken as 15 times the nominal diameter of the strand, or $190.5 \mathrm{~mm}$. Poisson's ratio of the prestressing steel was taken as $0 \cdot 3$. Analysis was carried out for this case according to the analytical model presented in chapter 3 of Costello's Theory of Wire Ropes (Costello, 1997). The loads carried by the helical wires and the central wire were determined to be $85 \cdot 29 \%$ and $14 \cdot 71 \%$ respectively of the total load applied. The share of each helical wire was $14 \cdot 21 \%$ of the total load. The share of loading among wires was not uniform, but reasonably close to the average value of $14 \cdot 29 \%$. In the elastic stage, once the mechanical properties are determined from the central wire, it is possible to calculate those for the entire strand. However, since the deviation from the average stress is so small, estimation of the mechanical properties of a strand based on those of the central wire is reasonably accurate even beyond the elastic stage.

\section{Experimental investigation}

\section{Test specimens and equipment}

Two different kinds of seven-wire strands were tested - grade 1860 steel conforming to GB/T 5224 used in Mainland China and grade 1860 steel conforming to BS 5896 used in European countries. As it is difficult to measure the strain of a strand accurately due to its helical structure, extracted central wires were tested and this allowed better clamping and control. Table 1 shows the nominal dimensions and properties of the central wire specimens, while Table 2 shows their chemical compositions.

A material testing system (MTS 810) of $250 \mathrm{kN}$ capacity was employed for the tests at The University of Hong Kong (HKU). The heating device was an MTS 653 high-temperature furnace with three heating chambers and a maximum heating temperature of $1400^{\circ} \mathrm{C}$. The central $185 \mathrm{~mm}$ portion of the specimen was heated inside the furnace, which was monitored by a temperature controller (MTS model 409.83). The strain of the heated part of the specimen was measured by an axial extensometer for high-temperature testing (MTS 632.54F-11), having a gauge length of $25 \mathrm{~mm}$ and a maximum strain of $10 \%$. The extensometer had two extension arms for convenient mounting. The centre-split design of the furnace allowed it to be opened slightly for the attachment and detachment of the extensometer while reducing adverse effects on the temperature inside the furnace. A thermocouple was placed in contact with the heated part of the specimen to measure its temperature.

\begin{tabular}{lcr}
\hline & GB/T 5224 & BS 5896 \\
\hline Diameter: mm & $4 \cdot 35$ & $5 \cdot 39$ \\
Area: $\mathrm{mm}^{2}$ & $14 \cdot 86$ & $22 \cdot 82$ \\
Density: kg/m & 7800 & 7800 \\
Total length: $\mathrm{mm}$ & 800 & 800 \\
Gripped length: mm & 150 & 150 \\
Clear length: mm & 650 & 650 \\
Young's modulus: GPa & 200 & $204 \cdot 1$
\end{tabular}

Table 1. Nominal dimensions and properties of central wire specimens

\begin{tabular}{lcc}
\hline & GB/T 5224 & BS 5896 \\
\hline Chromium: \% & - & 0.13 \\
Manganese: \% & 0.73 & 0.74 \\
Silicon: \% & 0.2 & 0.41 \\
Phosphorus: \% & 0.015 & $<0.01$ \\
Carbon: \% & 0.8 & 0.8 \\
Sulfur: \% & 0.008 & 0.016
\end{tabular}

Table 2. Chemical compositions of prestressing steel wire 
Magazine of Concrete Research Volume 69 Issue 8
Mechanical properties of prestressing

steel in and after fire

Zhang, Wei, Au and Li
The whole testing system was covered with an aluminium foil heating shield for temperature stabilisation, as shown in Figure 1.

\section{Test procedure}

In the tensile tests at elevated temperatures, each specimen was heated to a target temperature (i.e. $100-800^{\circ} \mathrm{C}$ ) and maintained for $15 \mathrm{~min}$ with one end gripped and the other end free. Free expansion of the specimen was allowed before applying load to avoid any influence of thermal expansion on strain measurements. Afterwards, the free end was gripped and the extensometer was attached to the heated part of the specimen. A constant displacement-controlled loading rate of $2 \mathrm{~mm} / \mathrm{min}$ was applied until the specimen ruptured. The extensometer was detached before the specimen failed to protect the extension rods. The data obtained showed that the strain rate was approximately $0 \cdot 003 / \mathrm{min}$, which fell into the range of $0 \cdot 005 \pm 0 \cdot 002 / \mathrm{min}$ as specified in ASTM E 21-09 (ASTM, 2009). The load and strain were recorded continuously by a computer at a sampling frequency of $5 \mathrm{~Hz}$.

In the tensile tests after cooling, each specimen was first heated to the target temperature and maintained constant for $15 \mathrm{~min}$ for stabilisation, with one end gripped and the other end free. The furnace was then switched off and opened slightly, allowing the specimen to cool naturally to ambient temperature. When the specimen reached ambient temperature $\left(25^{\circ} \mathrm{C}\right)$, the free end was gripped and a constant displacement-controlled loading rate of $2 \mathrm{~mm} / \mathrm{min}$ was applied until failure, as before.

\section{Test results}

\section{Mechanical properties at elevated temperatures}

The stress obtained was engineering stress, assuming a constant cross-sectional area and ignoring the necking effect. Young's modulus $E$ was taken as the tangent value of the initial proportional section of the stress-strain curve. The yield strength $f_{0.2 \%}$ was taken as the $0 \cdot 2 \%$ proof stress (non-proportional elongation). The ultimate strength $f_{\mathrm{u}}$ was the maximum stress in the stress-strain curve. Their corresponding values at elevated temperature $T^{\circ} \mathrm{C}$ were similarly defined, giving reduction factors (BSI, 2004) as $E(T) / E, f_{0 \cdot 2}(T) / f_{0 \cdot 2} \%$ and $f_{\mathrm{u}}(T) / f_{\mathrm{u}}$. The stress-strain curves of prestressing wires conforming to $\mathrm{GB} / \mathrm{T}$ 5224 and BS 5896 at elevated temperatures are plotted in Figures 2 and 3 respectively. Young's modulus, yield strength and ultimate strength are affected differently by temperatures above $200^{\circ} \mathrm{C}$. The corresponding reduction factors are shown in Table 3. They are also shown graphically in Figures 4-6 and compared with available results reported by Fan and Lv (2001, 2002), Fan (2004), Atienza and Elices (2009), Wang et al. (2010) and Gales et al. (2012) as summarised in Table 4.

Figure 4 shows that the Young's moduli of prestressing wires conforming to BS 5896 and GB/T 5224 showed similar degradation below $500^{\circ} \mathrm{C}$, but the wire conforming to $\mathrm{GB} / \mathrm{T} 5224$ deteriorated more above $500^{\circ} \mathrm{C}$. At temperatures of $600^{\circ} \mathrm{C}$,

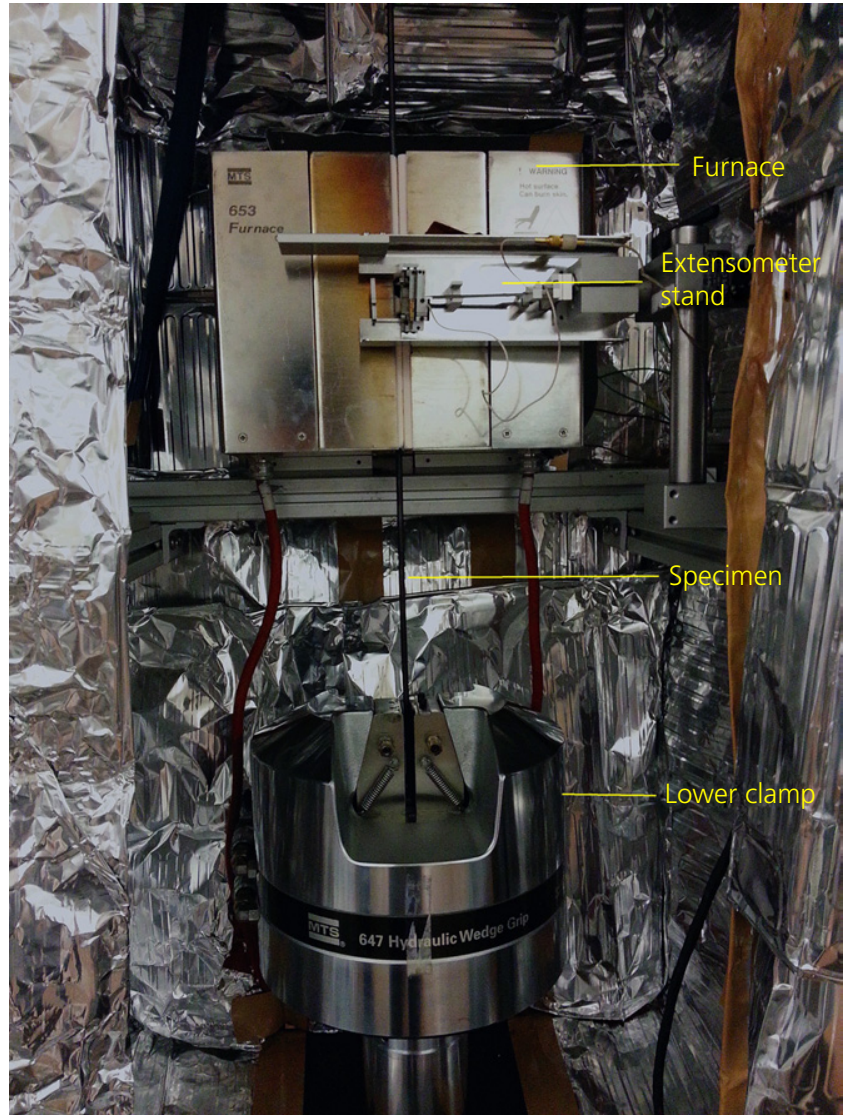

(a)

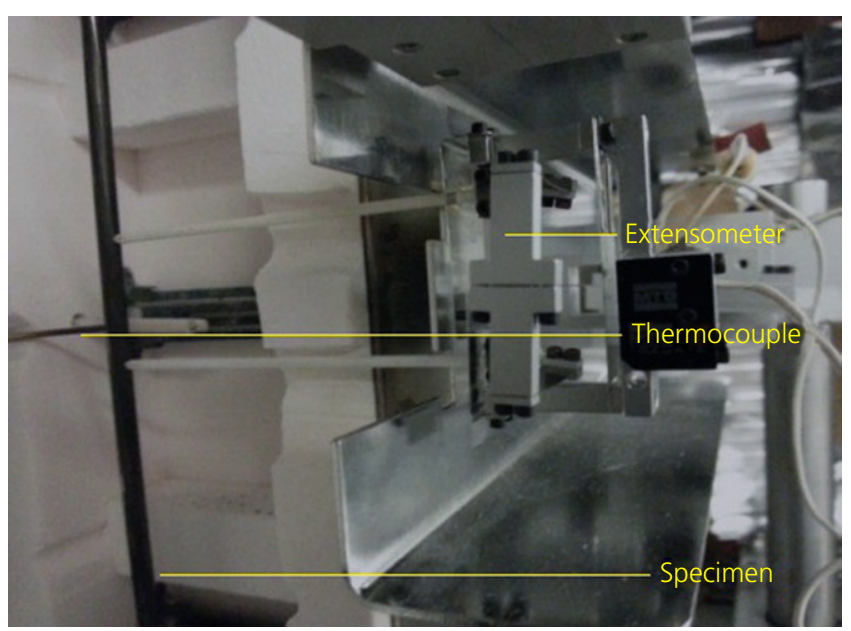

(b)

Figure 1. (a) MTS 810 material testing system with aluminium shield. (b) MTS 632.54F-11 axial extensometer

$700^{\circ} \mathrm{C}$ and $800^{\circ} \mathrm{C}$, the reduction factors for Young's modulus of prestressing wire conforming to BS 5896 were $46 \cdot 6 \%, 20 \cdot 5 \%$ and $18.2 \%$ respectively, while those for GB/T 5224 wire were only $37 \cdot 9 \%, 7 \cdot 3 \%$ and $3 \cdot 6 \%$. The BS 5896 prestressing steel wire showed better resistance above $500^{\circ} \mathrm{C}$ in terms of Young's 


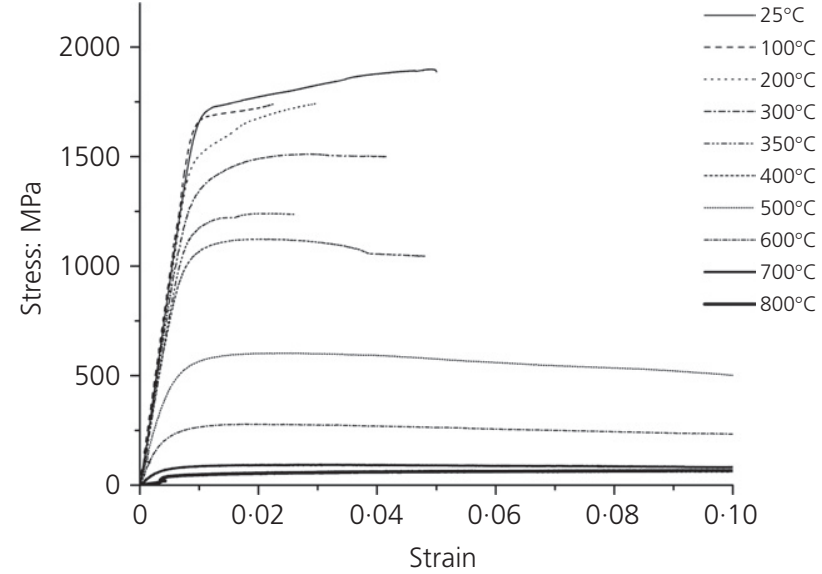

Figure 2. Stress-strain curves of prestressing wire conforming to GB/T 5224 at elevated temperatures

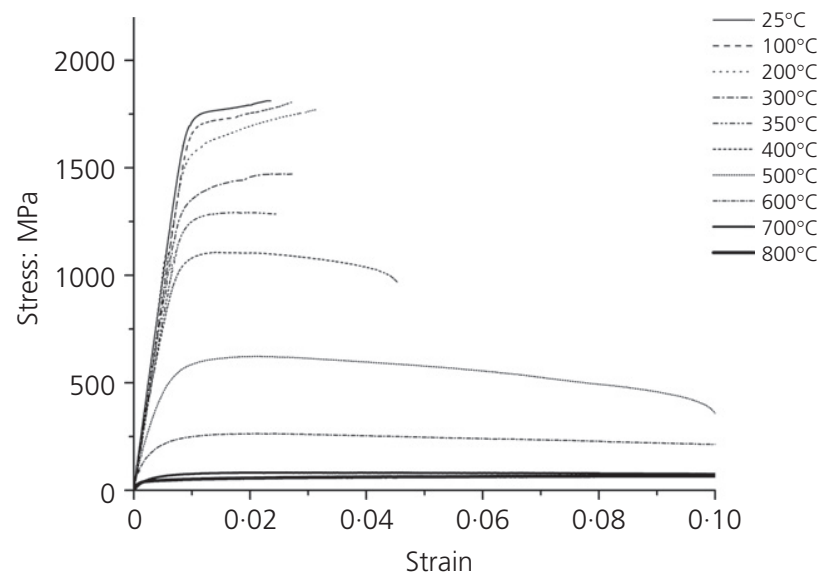

Figure 3. Stress-strain curves of prestressing wire conforming to BS 5896 at elevated temperatures modulus at elevated temperature. The values specified in BS EN 1992-1-2 (BSI, 2004) are conservative at temperatures of $500-800^{\circ} \mathrm{C}$ compared with those for BS 5896 , but the specified values are close to those for GB/T 5224. Most of the reduction factors for Young's modulus from other research works are lower at temperatures above $400^{\circ} \mathrm{C}$.

Figure 5 shows generally good agreement between the reduction factors for the yield strength of prestressing wires conforming to GB/T 5224 and BS 5896. The reduction factors for yield strength specified by BS EN 1992-1-2 are conservative at temperatures of $200-500^{\circ} \mathrm{C}$, but adequate for $500-800^{\circ} \mathrm{C}$. Figure 6 shows less variability in ultimate strength at elevated temperatures compared with yield strength. BS EN 1992-1-2 (BSI, 2004) gives conservative reduction factors for ultimate strength at temperatures of $200-500^{\circ} \mathrm{C}$, but agrees relatively well at other temperatures.

In general, a mechanical property $\xi(T)$ at temperature $T^{\circ} \mathrm{C}$ can be expressed as

1. $\xi(T)=\xi_{0} \times f(T)$

in terms of the mechanical property at ambient temperature $\xi_{0}$ and the corresponding mechanical reduction factor $f(T)$ (Hertz, 2004) given by

2. $f(T)=k+\frac{1-k}{1+(T / a)+(T / b)^{2}+(T / c)^{8}+(T / d)^{64}}$

where the parameters $k, a, b, c$ and $d$ can be determined from experimental data.

The reduction factors for Young's modulus, yield strength and ultimate strength at elevated temperatures of the prestressing

\begin{tabular}{|c|c|c|c|c|c|c|}
\hline \multirow[t]{2}{*}{ Temperature: ${ }^{\circ} \mathrm{C}$} & \multicolumn{3}{|c|}{ GB/T 5224} & \multicolumn{3}{|c|}{ BS 5896} \\
\hline & Young's modulus & Yield strength & Ultimate strength & Young's modulus & Yield strength & Ultimate strength \\
\hline 20 & 1.000 & 1.000 & $1 \cdot 000$ & 1.000 & 1.000 & 1.000 \\
\hline 100 & $1 \cdot 013$ & 0.985 & 0.998 & 0.944 & 0.974 & 0.984 \\
\hline 200 & 0.97 & $0 \cdot 888$ & 0.965 & 0.94 & 0.906 & $0 \cdot 949$ \\
\hline 300 & 0.886 & $0 \cdot 792$ & 0.796 & 0.858 & 0.779 & 0.754 \\
\hline 350 & 0.853 & $0 \cdot 677$ & 0.654 & $0 \cdot 817$ & $0 \cdot 717$ & 0.662 \\
\hline 400 & 0.829 & 0.607 & $0 \cdot 591$ & 0.798 & 0.607 & $0 \cdot 568$ \\
\hline 500 & $0 \cdot 578$ & $0 \cdot 295$ & $0 \cdot 318$ & $0 \cdot 571$ & $0 \cdot 301$ & $0 \cdot 319$ \\
\hline 600 & $0 \cdot 379$ & $0 \cdot 131$ & $0 \cdot 147$ & 0.466 & $0 \cdot 116$ & $0 \cdot 135$ \\
\hline 700 & 0.073 & 0.049 & 0.049 & $0 \cdot 205$ & 0.033 & 0.042 \\
\hline 800 & 0.036 & 0.027 & 0.035 & $0 \cdot 182$ & 0.025 & 0.034 \\
\hline
\end{tabular}

Table 3. Reduction factors for mechanical properties of prestressing steel wires conforming to $\mathrm{GB} / \mathrm{T} 5224$ and BS 5896 at elevated temperatures 


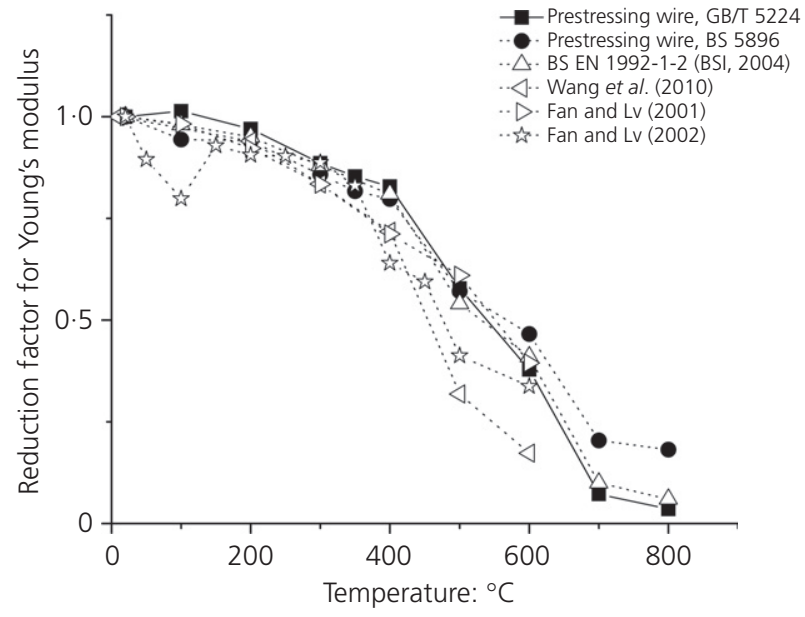

Figure 4. Reduction factors for Young's modulus at elevated temperatures

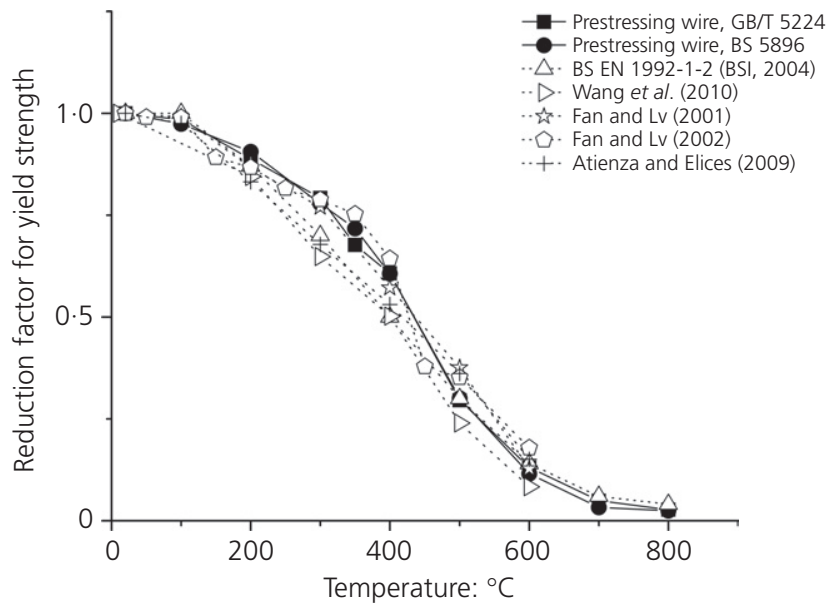

Figure 5. Reduction factors for yield strength at elevated temperatures

steels tested as obtained from curve fitting are shown in Figure 7. The values of adjusted $R^{2}$ for curve fitting are reasonably close to unity, indicating a good fit based on the experimental data. The corresponding parameters $k, a, b, c$ and $d$ of prestressing steel wires conforming to GB/T 5224 and BS 5896 prestressing steel are presented in Table 5.

\section{Mechanical properties after cooling}

The stress-strain curves of GB/T 5224 and BS 5896 prestressing wires after natural cooling from peak temperatures of $100-600^{\circ} \mathrm{C}$ to ambient temperature are shown in Figures 8 and 9 respectively. The mechanical properties are hardly affected by heating up to and cooling from $300^{\circ} \mathrm{C}$, but the residual strengths degrade after cooling from peak temperatures above $400^{\circ} \mathrm{C}$. As shown in Figure 10, upon cooling from

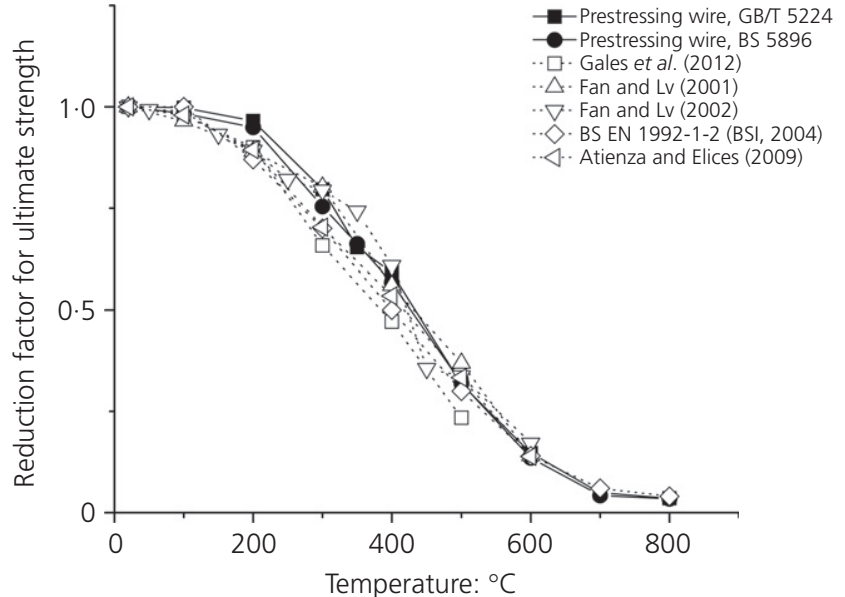

Figure 6. Reduction factors for ultimate strength at elevated temperatures

\begin{tabular}{lccccc} 
Author & $\begin{array}{c}\text { Diameter: } \\
\mathrm{mm}\end{array}$ & Grade & Standard & Strand Wire \\
\hline Fan and Lv (2002) & - & 1860 & - & $\sqrt{ }$ & \\
Fan (2004) & - & 1860 & - & $\sqrt{ }$ & \\
Fan and Lv (2001) & 5 & 1670 & GB/T 5224 & $\sqrt{ }$ \\
$\begin{array}{l}\text { Atienza and } \\
\quad \text { Elices (2009) }\end{array}$ & 5 & - & - & $\sqrt{ }$ \\
$\quad \begin{array}{l}\text { Wang et al. } \\
\quad \text { (2010) }\end{array}$ & 5 & 1670 & GB/T 5224 & $\sqrt{ }$ \\
Gales et al. (2012) & 4 & 1670 & BS 5896 & $\sqrt{ }$
\end{tabular}

Table 4. Previous tests of prestressing steel at elevated temperatures

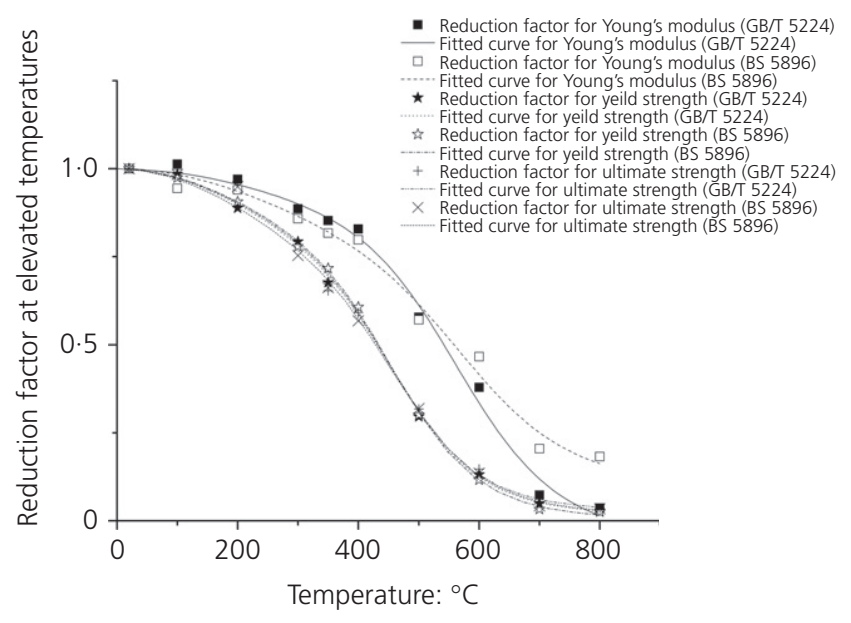

Figure 7. Reduction factors for mechanical properties of prestressing wire by curve fitting 


\begin{tabular}{lrrrrrr} 
& \multicolumn{1}{c}{ Steel } & \multicolumn{1}{c}{$k$} & $a$ & $b$ & $c$ & $d$ \\
\hline Young's modulus & GB/T 5224 & -0.0572 & $7.00 \times 10^{9}$ & $950 \cdot 37$ & $580 \cdot 74$ & 100000 \\
& BS 5896 & 0.0965 & $7.00 \times 10^{9}$ & 724.35 & 589.82 & 100000 \\
Yield strength & GB/T 5224 & 0.0142 & $7.07 \times 10^{9}$ & 594.12 & 469.91 & 100000 \\
& BS 5896 & 0.0027 & $7.00 \times 10^{9}$ & 623.26 & 470.6 & 100000 \\
Ultimate strength & GB/T 5224 & 0.0257 & $8.00 \times 10^{9}$ & 602.83 & 467.09 & 100000 \\
& BS 5896 & 0.0159 & $7.00 \times 10^{9}$ & 564.32 & 473.03 & 100000
\end{tabular}

Table 5. Parameters for reduction factors for mechanical properties at elevated temperatures

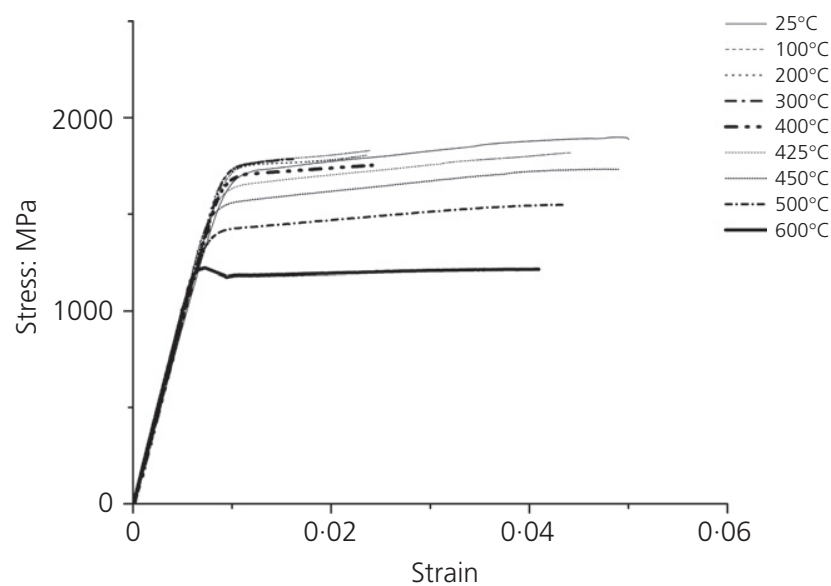

Figure 8. Stress-strain curves of prestressing wire conforming to $\mathrm{GB} / \mathrm{T} 5224$ after cooling from temperatures up to $500^{\circ} \mathrm{C}$

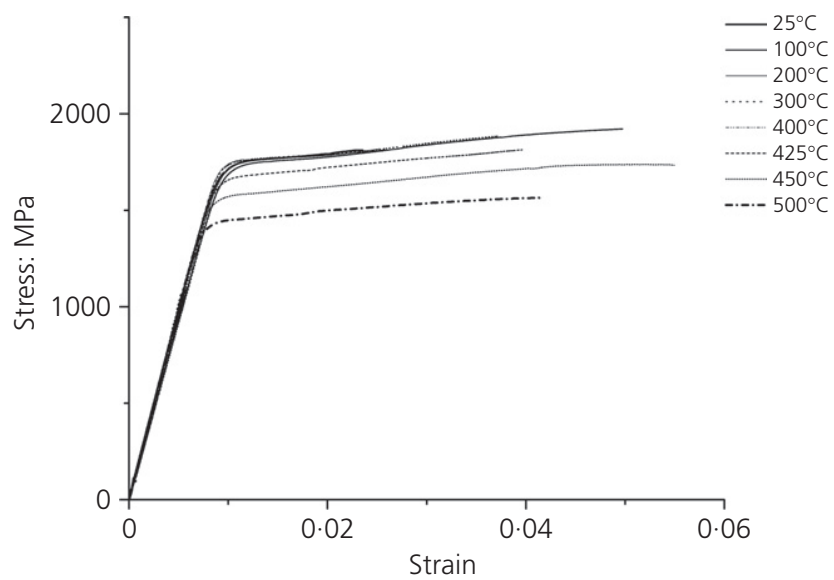

Figure 9. Stress-strain curves of prestressing wire conforming to BS 5896 after cooling from temperatures up to $500^{\circ} \mathrm{C}$

temperatures of $600^{\circ} \mathrm{C}$ or above, the elastic range is adversely affected and plastic deformation begins earlier. This is probably because of the high-temperature exposure followed by slow cooling, which resembles annealing. After cooling from $800^{\circ} \mathrm{C}$, the prestressing steel behaves similarly to high-yield steel.

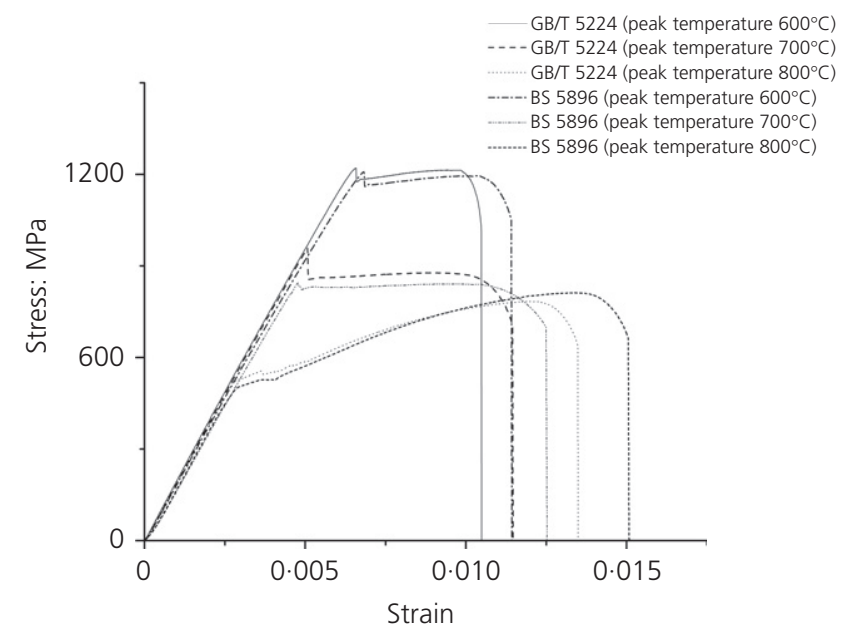

Figure 10. Stress-strain curves after cooling from temperatures of $600^{\circ} \mathrm{C}$ and above

To avoid damage to the extensometer by premature failure in tests after cooling from $600^{\circ} \mathrm{C}$ or above, the strain was estimated from cross-head displacement. Where both upper and lower yield points appeared, the yield strength was based on the lower. The reduction factors for Young's modulus, yield strength and ultimate strength after cooling are presented in Table 6.

Figure 11 compares the reduction factors for Young's modulus after natural cooling $\left(E_{\mathrm{ac}}(T) / E\right)$ with available results; $E_{\mathrm{ac}}(T)$ is Young's modulus after cooling from the peak temperature $T^{\circ} \mathrm{C}$ and $E$ is that at ambient temperature. Among the cooling conditions investigated by Fan (2004) (natural cooling, water-spray cooling, in-furnace cooling and $72 \mathrm{~h}$ after natural cooling), only the results for natural cooling are included in Figure 11. In general, Young's modulus of prestressing steel is largely recoverable after exposure to elevated temperature and cooling.

The reduction factors for yield strength $f_{\text {yac }}(T)$ of prestressing steel wire conforming to GB/T 5224 and BS 5896 after cooling from the peak temperature $T^{\circ} \mathrm{C}$ in Figure 12 show an obvious decline for peak temperatures of $400^{\circ} \mathrm{C}$ or above but little effect below $400^{\circ} \mathrm{C}$. The results from other sources show 
$\mathrm{GB} / \mathrm{T} 5224$

\begin{tabular}{r}
\hline Young \\
modulus \\
1.000 \\
1.032 \\
1.052 \\
1.043 \\
1.049 \\
1.032 \\
1.064 \\
1.055 \\
1.073 \\
1.028 \\
1.056
\end{tabular}

Yield
strength

\section{0}

100

200

300

400

425

450

500

600

700

800

$\begin{array}{ll}1.000 & 1.000 \\ 1.026 & 1.024 \\ 1.022 & 1.028 \\ 1.028 & 1.019 \\ 0.995 & 0.985 \\ 0.964 & 0.966 \\ 0.912 & 0.913 \\ 0.83 & 0.818 \\ 0.689 & 0.643 \\ 0.497 & 0.504 \\ 0.343 & 0.413\end{array}$

Ultimate strength

Table 6. Reduction factors for mechanical properties of prestressing steel wires conforming to GB/T 5224 and BS 5896 after cooling
BS 5896

\begin{tabular}{lcc}
\hline $\begin{array}{c}\text { Young's } \\
\text { modulus }\end{array}$ & $\begin{array}{c}\text { Yield } \\
\text { strength }\end{array}$ & $\begin{array}{c}\text { Ultimate } \\
\text { strength }\end{array}$ \\
1.000 & 1.000 & 1.000 \\
0.956 & 0.984 & 0.985 \\
0.98 & 0.996 & 0.966 \\
1.007 & 1.012 & 0.997 \\
1.007 & 1.015 & 0.982 \\
0.992 & 0.967 & 0.939 \\
1.012 & 0.917 & 0.89 \\
1.023 & 0.845 & 0.805 \\
1.014 & 0.693 & 0.619 \\
0.946 & 0.484 & 0.433 \\
0.978 & 0.334 & 0.416
\end{tabular}

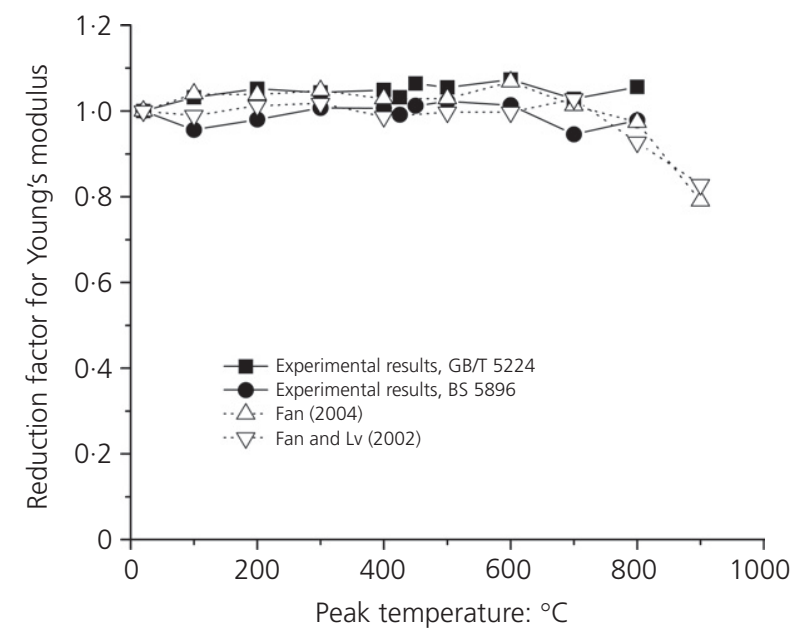

Figure 11. Reduction factors for Young's modulus after cooling

similar trends, but the present results appear more consistent. The reversed trend of results from Fan (2004) for cooling from temperatures above $700^{\circ} \mathrm{C}$ could be caused by strength enhancement because of martensite formation due to rapid cooling from the critical forming temperature $723^{\circ} \mathrm{C}$ (Meyers and Chawla, 2009). Similar trends can also be observed for the reduction factors for ultimate strength $f_{\text {uac }}(T)$ of prestressing steel wire conforming to GB/T 5224 and BS 5896 after cooling from the peak temperature $T^{\circ} \mathrm{C}$, as shown in Figure 13 .

Based on the test results, Young's modulus after cooling from peak temperature $T$ can be regarded as unchanged, that is

3. $E_{\mathrm{ac}}(T)=E_{0}$

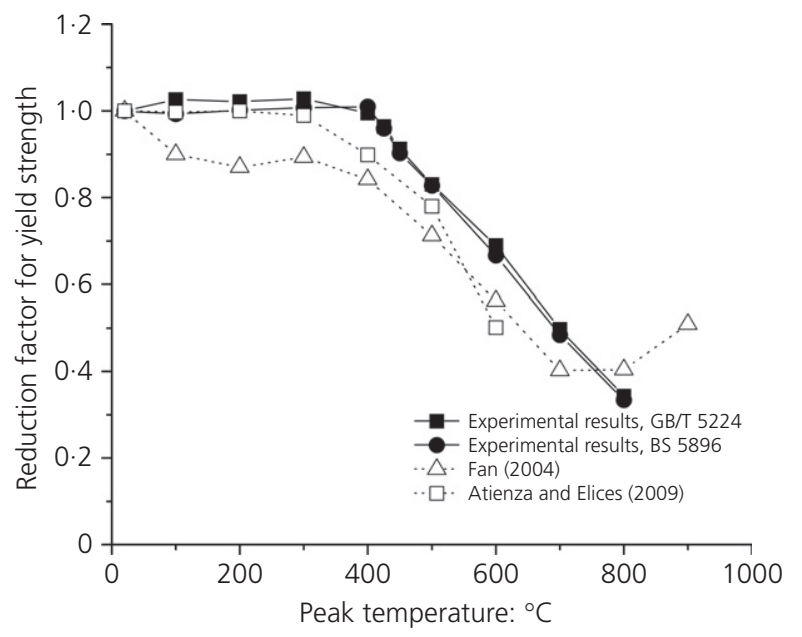

Figure 12. Reduction factors for yield strength after cooling

Based on the test results, piecewise linear functions were employed to describe the reduction factors for residual yield and ultimate strengths after cooling. The reduction factors for yield and ultimate strengths of prestressing steel wire conforming to GB/T 5224 are given respectively as

$$
\text { 4. } f_{\mathrm{yac}}(T)= \begin{cases}1 & 20^{\circ} \mathrm{C}<T<400^{\circ} \mathrm{C} \\ 1.65469-0.00164 T & 400^{\circ} \mathrm{C} \leq T \leq 800^{\circ} \mathrm{C}\end{cases}
$$

5. $f_{\text {uac }}(T)= \begin{cases}1 & 20^{\circ} \mathrm{C}<T<400^{\circ} \mathrm{C} \\ 1.655-1.64 \times 10^{-3} T & 400^{\circ} \mathrm{C} \leq T \leq 700^{\circ} \mathrm{C} \\ 1.142-9.175 \times 10^{-4} T & 700^{\circ} \mathrm{C} \leq T \leq 800^{\circ} \mathrm{C}\end{cases}$ 


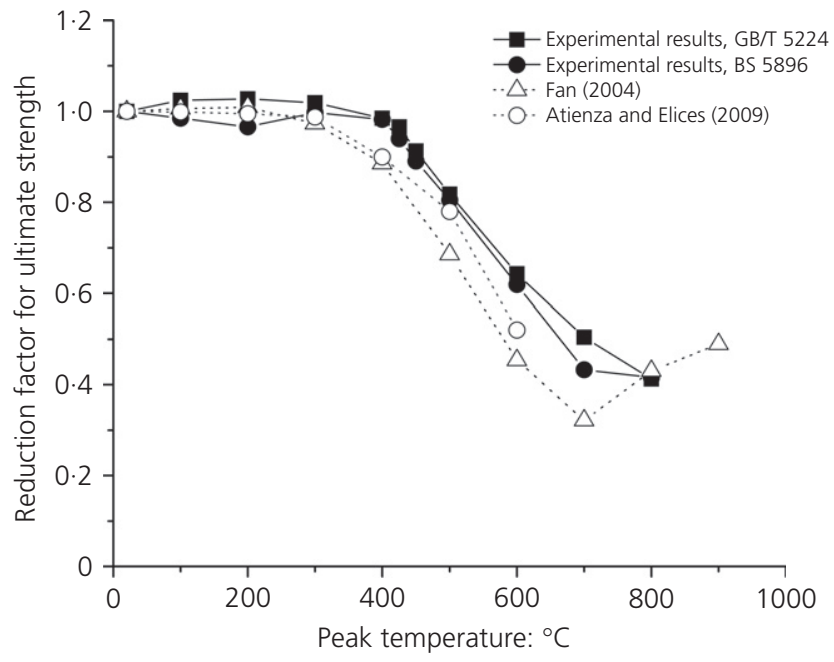

Figure 13. Reduction factors for ultimate strength after cooling

Similarly, those for prestressing steel wire conforming to BS 5896 are given respectively as
6. $f_{\mathrm{yac}}(T)=\left\{\begin{array}{l}1 \\ 1\end{array}\right.$
$1.707-1.76 \times 10^{-3} T$
$20^{\circ} \mathrm{C}<T<400^{\circ} \mathrm{C}$
$400^{\circ} \mathrm{C} \leq T \leq 800^{\circ} \mathrm{C}$

7. $f_{\text {uac }}(T)= \begin{cases}1 & 20^{\circ} \mathrm{C}<T<400^{\circ} \mathrm{C} \\ 1.71708-1.83 \times 10^{-3} T & 400^{\circ} \mathrm{C} \leq T \leq 700^{\circ} \mathrm{C} \\ 0.55074-1.684 \times 10^{-4} T & 700^{\circ} \mathrm{C} \leq T \leq 800^{\circ} \mathrm{C}\end{cases}$

\section{Effects of heating and cooling}

Figure 14 compares the reduction factors for Young's modulus at elevated temperatures and after cooling, which is characterised by full recovery upon cooling. However, despite the full recovery of Young's modulus upon cooling, the reduction of Young's modulus during heating will have caused substantial loss of prestress, thereby affecting the load-carrying capacity even though the peak temperature may not be too high. Figures 15 and 16 show the corresponding comparisons for yield and ultimate strengths, which display striking similarity. The residual strengths of prestressing steel are essentially fully recovered if the peak temperature does not exceed $400^{\circ} \mathrm{C}$.

\section{Mechanical properties of strands in prestressed concrete after fire test}

Under the same research project, fire tests on a number of unbonded post-tensioned two-way concrete slab specimens (Wei et al., 2014) were carried out in a furnace at South China University of Technology (SCUT) to investigate their structural fire performance. Grade 1860 prestressing steel strands

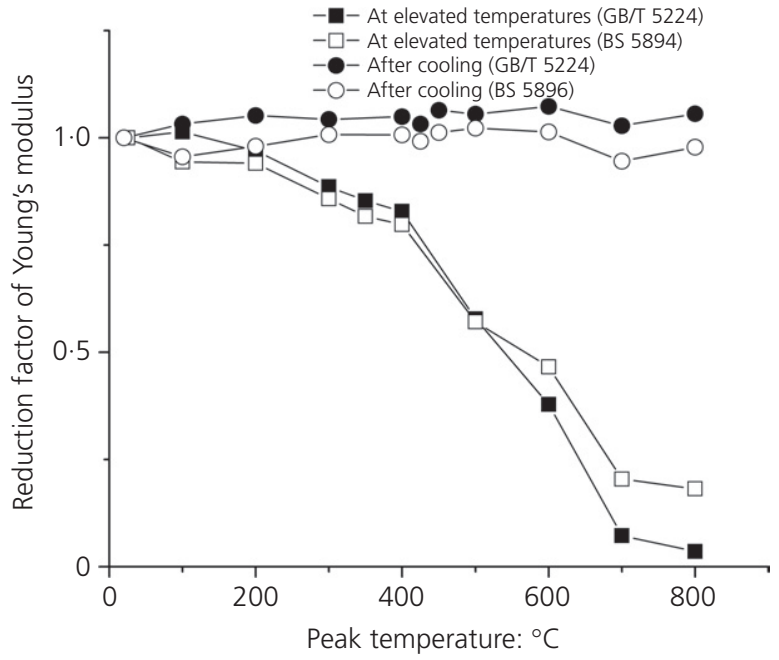

Figure 14. Reduction factors for Young's modulus at elevated temperatures and after cooling

conforming to GB/T 5224 were used as tendons. After fire testing, samples of strands were reclaimed from the four specimens tested to determine their residual strengths after exposure to elevated temperatures. The length of each strand specimen was $1100 \mathrm{~mm}$ with a nominal cross-sectional area of $98.7 \mathrm{~mm}^{2}$. Each strand had experienced different peak temperatures, as measured by thermocouples provided at key locations and recorded by a datalogger.

Additional precautions were necessary for the tensile tests at ambient temperature as the strand samples were imperfect. To avoid slipping at the grips, additional aluminium clamps

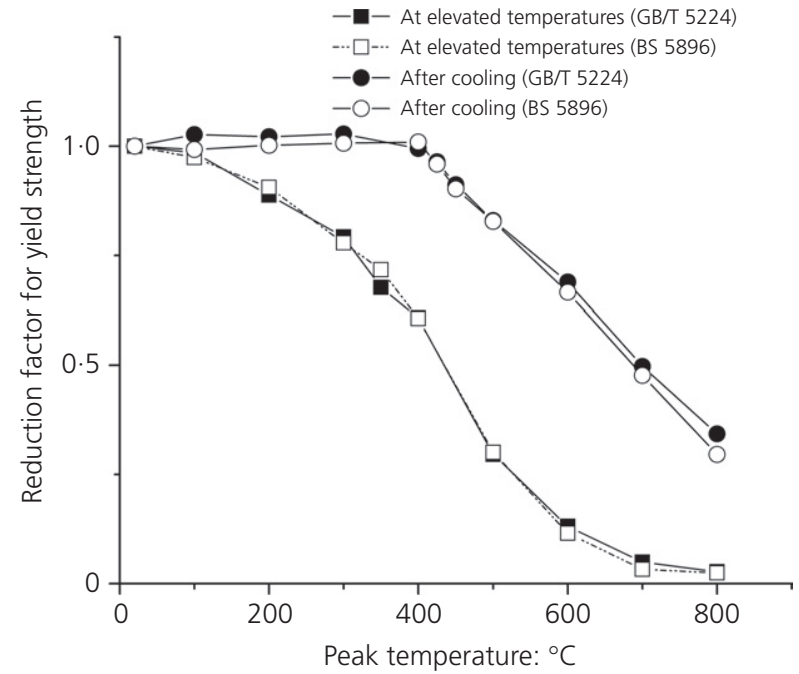

Figure 15. Reduction factors for yield strength at elevated temperatures and after cooling 
roughened with ironsand at the surfaces were used. An extensometer of gauge length of $500 \mathrm{~mm}$ was used to monitor the strain. Each strand specimen was loaded until its ultimate strength was reached. The extensometer was detached before failure of the specimen for protection of the instrument. The yield and ultimate strengths obtained from the reclaimed strands (SCUT) are plotted against the peak temperatures experienced in Figure 17. Also shown in the figure are the corresponding values obtained from the testing of the central wire (HKU). In general, the trends agree well, but the degradation of the reclaimed strands appears to be more serious. The machine used for testing the strands was not as accurate as that used for testing the central wires, although this may not explain the higher degradation. The post-tensioned concrete specimens had been left outdoors for a year before fire testing,

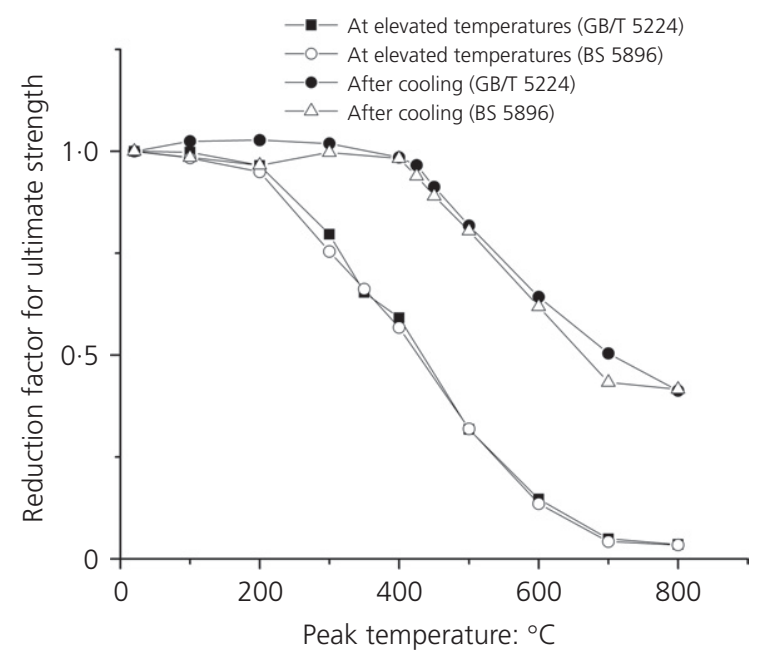

Figure 16. Reduction factors for ultimate strength at elevated temperatures and after cooling

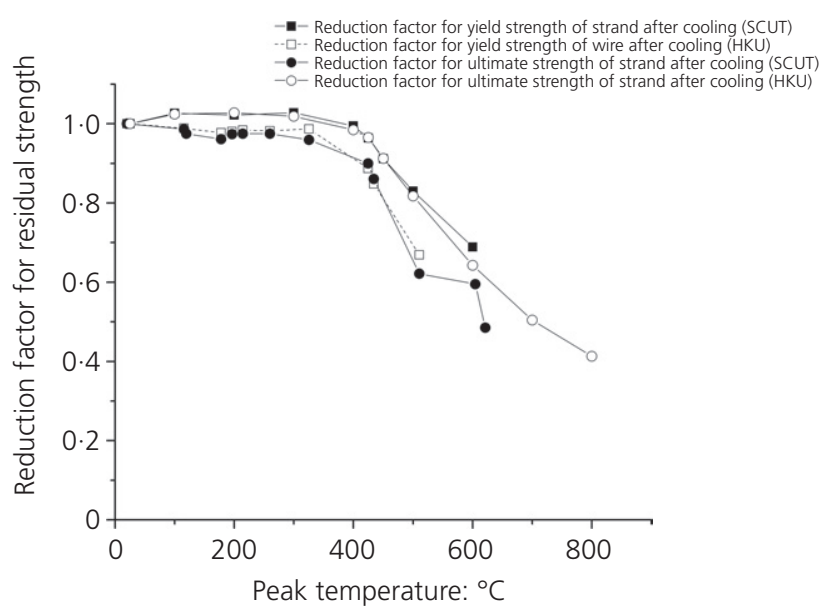

Figure 17. Comparison of residual strengths of prestressing strand and wire after cooling during which some minor corrosion could have taken place, thus slightly reducing the cross-sectional area. Moreover, the slab specimen was exposed to fire at the soffit, creating a rather large thermal gradient; therefore, different wires of a strand experienced different peak temperatures. During subsequent tensile testing, the most affected wire could fail first and trigger earlier strand failure.

\section{Conclusions}

The mechanical properties of prestressing strands from two different sources in and after fire were investigated. The results are generally consistent with available results from the research literature and design codes. Empirical formulae based on a unified model are proposed for the degradation of Young's modulus, yield strength and ultimate strength of prestressing steel both at elevated temperatures and after cooling to ambient temperature. Although Young's modulus was found to be largely recoverable upon cooling to ambient temperature, both yield strength and ultimate strength suffered permanent degradation. To assist in post-fire assessments of prestressed concrete structures, it is recommended that reduction factors for the key mechanical properties after fire and cooling be incorporated in the relevant design codes.

\section{Acknowledgements}

The work described here was supported by the Research Grants Council (RGC) of the Hong Kong Special Administrative Region, China (RGC project no. HKU 710012E) and the State Key Laboratory of Subtropical Building Science of South China University of Technology, China (project no. 2011KA02). The authors are grateful to VSL Hong Kong Ltd for the provision of some strands and to Mr Ran Wang for assistance in the work.

\section{REFERENCES}

ASTM (2009) E 21-09: Standard test methods for elevated temperature tension tests of metallic materials. ASTM International, West Conshohocken, PA, USA.

Atienza JM and Elices M (2009) Behavior of prestressing steels after a simulated fire: fire-induced damages. Construction and Building Materials 23(8): 2932-2940.

Bailey CG and Ellobody E (2009) Fire tests on unbonded post-tensioned one-way concrete slabs. Magazine of Concrete Research 61(1): 67-76, http://dx.doi.org/10.1680/ macr.2008.00005.

BSI (2004) BS EN 1992-1-2: Eurocode 2: Design of concrete structures - part 1-2: general rules - structural fire design. BSI, London, UK.

BSI (2012) BS 5896: Specification for high tensile steel wire and strand for the prestressing of concrete. BSI, London, UK.

Costello GA (1997) Theory of Wire Ropes. Springer, New York, NY, USA. 
Fan J (2004) Experimental study on material properties of prestressed steel strand post high temperature. Journal of Nanjing University of Science and Technology 28(2): 186-189 (in Chinese).

Fan J and Lv ZT (2001) Experimental research on performance of prestressed steel wire in high temperature environment. Architecture Technology 32(12): 833-834 (in Chinese).

Fan J and Lv ZT (2002) Experimental study on material properties of prestressed steel wire post high temperatures. Industrial Construction 32(9): 30-32 (in Chinese).

Gales J, Bisby L and Stratford T (2012) High temperature creep deformation and failure behavior of prestressing steel. Proceedings of 7th International Conference on Structures in Fire (SiF 2012), ETH Zurich, Institute of Structural Engineering, Zurich, Switzerland, pp. 659-668.

Gálvez F, Atienza JM and Elices M (2011) Behaviour of steel prestressing wires under extreme conditions of strain rate and temperature. Structural Concrete 12(4): 255-261.

Hertz KD (2004) Reinforcement data for fire safety design. Magazine of Concrete Research 56(8): 453-459, http://dx. doi.org/10.1680/macr.2004.56.8.453.

Hertz KD (2006) Quenched reinforcement exposed to fire. Magazine of Concrete Research 58(1): 43-48, http://dx.doi.org/10.1680/macr.2006.58.1.43.
Meyers M and Chawla K (2009) Mechanical Behavior of Materials. Cambridge University Press, Cambridge, UK. Neves IC, Rodrigues JPC and Loureiro AP (1996) Mechanical properties of reinforcing and prestressing steels after heating. Journal of Materials in Civil Engineering ASCE 8(4): 189-194.

Pang PTC (2006) Fire engineering design and post fire assessment. The Structural Engineer 84(20): 23-29.

SAC (Standardization Administration of China) (2003) GB/T 5224: Steel strand for prestressed concrete. Ministry of Construction of the People's Republic of China, Beijing, China (in Chinese).

Wang Y, Shen Z and Li Y (2010) Experimental study of mechanical properties of prestressed steel wire at elevated temperatures. Proceedings of 6th International Conference on Structures in Fire (SiF 2010), DEStecch Publications, Inc., Lancaster, PA, USA, pp. 711-718.

Wei Y, Au FTK, Li J and Tsang NCM (2014) Experimental and numerical investigation of post-tensioned concrete flat slabs in fire. Proceedings of 8 th International Conference on Structures in Fire (SiF 2014), Tongji University Press, Shanghai, China, pp. 229-238.

Zhang DS, Dong YL and Fang YY (2014) Behaviour of full-scale two-way simply supported concrete slabs in fire. Magazine of Concrete Research 66(16): 836-844, http://dx.doi.org/ 10.1680/macr.13.00352.

\section{HOW CAN YOU CONTRIBUTE?}

To discuss this paper, please submit up to 500 words to the editor at journals@ice.org.uk. Your contribution will be forwarded to the author(s) for a reply and, if considered appropriate by the editorial board, it will be published as a discussion in a future issue of the journal. 